\title{
Hypo-Calories with Micronutrients and Fat Emulsion of Pre-Operative Peripheral Parenteral Nutrition in Malnutrition Risk Rectal Cancer Patients: A Retrospective Cross-Sectional Study
}

\author{
Ming-Yi Liu ${ }^{1,5}$, Hsiu-Chih Tang ${ }^{2}$, Hui-Lan Yang ${ }^{3}$, Hsiu-Hua Huang ${ }^{4}$, Sue-Joan Chang ${ }^{5 *}$ \\ ${ }^{1}$ Department of Nutrition, Sin-Lau Hospital, Tainan, Chinese Taipei; ${ }^{2}$ Department of Surgery, Sin-Lau Hospital, Tainan, Chinese \\ Taipei; ${ }^{3}$ Department of Nursing, Sin-Lau Hospital, Tainan, Chinese Taipei; ${ }^{4}$ Department of Food and Nutrition, Taipei Veterans \\ General Hospital, Chinese Taipei; ${ }^{5}$ Department of Life Sciences, College of Bioscience and Biotechnology, National Cheng Kung \\ University, Tainan, Chinese Taipei. \\ Email: *sjchang@mail.ncku.edu.tw
}

Received May $5^{\text {th }}, 2013$; revised June $5^{\text {th }}, 2013$; accepted June $12^{\text {th }}, 2013$

Copyright (C) 2013 Ming-Yi Liu et al. This is an open access article distributed under the Creative Commons Attribution License, which permits unrestricted use, distribution, and reproduction in any medium, provided the original work is properly cited.

\begin{abstract}
Malnutrition has been recognized as a significant risk factor for the post operated patients, especially for those patients undergoing abdominal operations. This study evaluated the effect of hypo-calories with micronutrients of pre-operative peripheral parenteral nutrition support (PPPN) for rectal cancer patients. Retrospective cross sectional study method was used to investigate. We screened rectal cancer patients past year pre-operative with malnutrition risk from our cancer database and divided into 2 groups, received or not received PPPN and compared the post-operative outcomes. The results showed that the post-operative serum albumin of the 25 patients received PPPN averaged $2.5 \pm 0.32 \mathrm{~g} / \mathrm{dl}$; significantly better than those of the 15 patients not received PPPN (non-PPPN), which averaged $1.92 \pm 0.42 \mathrm{~g} / \mathrm{dl}$. The first ambulatory time required $3.0 \pm 0.8$ days for the PPPN, significantly shorter than those for the non-PPPN, which averaged $4.9 \pm 2.4$ days. Post-operative hospital days for the patients received PPPN were $18.2 \pm 10.5$ day, also significantly fewer than the non-PPPN, which averaged $33.7 \pm 20.0$ day. More than $25 \%$ of the non-PPPN was infected with sepsis, while none was infected in the PPPN patients. In conclusion, this study verified the benefits of micronutrients of pre-operative peripheral parenteral nutrition support for rectal cancer patients.
\end{abstract}

Keywords: Parenreral Nutrition; Pre-Operative Nutrition Support; Malnutrition; Rectal Cancer

\section{Introduction}

Many factors affect nutrient intake in surgical patients and resulting in malnutrition, hypoalbuminemia and immune dysfunction [1-4]. The stress response after surgery increased catabolic hormones and decreased anabolism [5]. For surgical patients, these would reduce the tolerance and retard recovery. Patients with surgical stress face many challenges, including maintaining a good nutritional status and avoiding weight loss and malnutrition. In the past, the nutrition supplies for surgical patients were always intervention post operation. However, the post-operative nutritional supports for these patients often do not match the requirements to improve the nutriational status. Klein et al. proposed pre-operative nutria-

\footnotetext{
*Corresponding author.
}

tional support could improve the patients' tolerance and outcomes for surgery, especially for patients of malnutrition before major surgery [6]. The nutrition assessment for patients before surgery, weight change and Prognostic Nutritional Index (PNI) is usually to assess the nutriational status. Nevertheless, the PNI is more sophisticated; it considers serum albumin level, triceps skin fold thickness, skin antigen test, and transferring [7]. Body weight and serum albumin value both were readily measurable and regarded as vital data for patients nutrition assessment $[8,9]$. The study demonstrated that when serum albumin values were less than $3.5 \mathrm{~g} / \mathrm{dl}$, or patients' body weights decreased $5 \%$ in a month, or $10 \%$ in six months, or patients who were fasting for 7 to 10 days before surgery were in need of nutritional support [9]. Enteral feeding was a preferred route for pre-operative nutrition 
support. Enteral nutrition in gastroenterology could promote the portal circulation, stimulated hormone secretion, modulated immune function and maintained the barrier function of the intestinal mucosa [10-12].

Most of the abdominal surgical patients with severe malnutrition were caused by gastrointestinal dysfunction and need nutritional support. Total Parenteral Nutrition (TPN) was a common method of nutritional support to compensate for the deficiency of enteral nutrition [13,14], but there were more risks associated with TPN, including pneumothorax, hemothorax, and Central Vein Catheter infection. Peripheral Parenteral Nutrition (PPN) was easy to use and had lower risk in comparison with TPN; however, the formula of PPN we generally use often did not provide enough energy or nutrients. In order to achieve complete nutrition, more active nutritional support is essential to improve patient's tolerance and outcomes, specifically PPN with fat emulsion infusion, vitamins and trace elements should be applied.

The aims of this study were to investigate the outcomes and prognosis of PPN with fat emulsion, vitamins and trace elements, acting as a pre-operative nutrition support on rectal cancer patients, and to explore for more convenient and effective nutritional support methods for surgical patients.

\section{Materials and Methods}

\subsection{Patients}

In this study, retrospective cross sectional study method was deployed to investigate whether pre-operative hypocalories with micronutrients and fat emulsion PPN support would improve the post-operative nutritional conditions. We screened rectal cancer patients of year 20092011 with pre-operative malnutrition from cancer database of Sin-Lau hospital. The patients were divided into two groups, the pre-operative PPN receiving group (PPPN) or the pre-operative PPN not receiving group (non-PPPN). However, the End-Stage Renal Disease patients in the pre-operative, the patients were diagnosed by physician as in need of emergency surgery and the post-operative patients with short bowel syndrome were excluded from this study. Patients' data acquisition and subsequent use were also approved by the institutional review board of the Sin-Lau Hospital. Non-PPPN patients did not receive pre-operative PPN as they refused hospitalized before surgery. And the Nutritional support period was less than three days, too short to be categorized into a non-PPPN group.

\subsection{Nutritional Risk Screening}

Malnutrition risk was evaluated based on the Malnutri- tion Screening Tool (MST) [15-17]. The MST is a quick and simple nutrition screening tool based on weight loss and appetite changes. Subjects with a score of 2 or more were subsequently classified as at risk of malnutrition (Table 1).

\subsection{Application of Pre-Operative Nutrition Support}

When a patient has been recognized as malnutrition before surgery, we used two PPN formulas (Table 2, Figure 1) to pre-operative support immediately. The PPN-A formula using glucose as the main energy source for the non-diabetic patients, PPN-B formula with glycerol as the main energy provided to diabetes patients [18]. Patients received $1500 \mathrm{ml}$ PPN solution and $200 \mathrm{ml}$ of a

\begin{tabular}{l}
\hline \\
Ascorbic Acid $100 \mathrm{mg}$ \\
Vitamin A. 3300 IU \\
Vitamin D $200 \mathrm{IU}$ \\
Thiamin $3 \mathrm{mg} 10 \mathrm{ml}$ \\
Riboflavin $3.6 \mathrm{mg}$ \\
Pyridoxine $4 \mathrm{mg}$ \\
Niacin $40 \mathrm{mg}$ \\
Pantothenic-Acid $15 \mathrm{mg}$ \\
Vitamin E $10 \mathrm{IU}$ \\
Biotin $60 \mathrm{mcg}$ \\
Folic Acid $400 \mathrm{mcg}$ \\
Vitamin B12 $5 \mathrm{mcg}$ \\
Zn $3.0 \mathrm{mg}$ \\
Copper $1.0 \mathrm{mg}$ \\
Mn $0.4 \mathrm{mg}$ \\
Cr $0.01 \mathrm{mcq} \quad$ Trace elements $2 \mathrm{ml}$ \\
I $0.056 \mathrm{mcq} \quad$ Zinc Sulfate injection $2 \mathrm{ml}$ \\
Zinc Sulfate Heptahydrate $11.88 \mathrm{mg}$ \\
Eq. to Zinc $2.7 \mathrm{mg}$
\end{tabular}

Figure 1. The ingredients of vitamins and minerals added to the $1500 \mathrm{ml}$ PPN solution.

Table 1. Malnutrition Screening Tool (MST).

Has the resident/patient lost weight recently without trying?

$\begin{array}{cl}\text { No } & 0 \\ \text { Unsure } & 2\end{array}$

Yes, how much?

$\begin{array}{cc}1-5 \mathrm{~kg} & 1 \\ 6-10 \mathrm{~kg} & 2 \\ 11-15 \mathrm{~kg} & 3 \\ >15 \mathrm{~kg} & 4\end{array}$

Has the resident/patient been eating poorly because of a decreased appetite? No 

Malnutrition Risk Rectal Cancer Patients: A Retrospective Cross-Sectional Study

Table 2. Two kinds of peripheral parenteral nutrition formulations ingredients.

\begin{tabular}{|c|c|c|c|c|c|c|c|c|c|c|c|}
\hline Formulas & Glucose (\%) & $\begin{array}{l}\text { Glycerol } \\
(\%)\end{array}$ & $\begin{array}{l}\text { Amino acid } \\
(\%)\end{array}$ & $\begin{array}{c}\mathrm{Na} \\
\mathrm{mEq} / \mathrm{L}\end{array}$ & $\begin{array}{c}\mathrm{K} \\
\mathrm{mEq} / \mathrm{L}\end{array}$ & $\begin{array}{c}\mathrm{Cl} \\
\mathrm{mEq} / \mathrm{L}\end{array}$ & $\begin{array}{c}\mathrm{Mg} \\
\mathrm{mEq} / \mathrm{L}\end{array}$ & $\begin{array}{c}\mathrm{Ca} \\
\mathrm{mEq} / \mathrm{L}\end{array}$ & $\begin{array}{c}\mathrm{P} \\
\mathrm{mM} / \mathrm{L}\end{array}$ & $\begin{array}{l}\text { Acetate } \\
\mathrm{mEq} / \mathrm{L}\end{array}$ & $\mathrm{Kcal} / \mathrm{L}$ \\
\hline PPN-A & 7.5 & - & 2.75 & 30.0 & 25.0 & 50.0 & 3.0 & - & 3.0 & - & 365 \\
\hline PPN-B & - & 3.0 & 2.9 & 34.5 & 23.7 & 40.5 & 4.9 & 3.0 & 3.5 & 46.4 & 243 \\
\hline \multicolumn{12}{|c|}{$\begin{array}{l}\text { Other nutrients added: Zinc Sulfate injection } 2 \mathrm{ml} / \text { day; Infuvita }{ }^{\circledR} \text { injection } 10 \mathrm{ml} / \text { day; Trace elements: } \\
\qquad 2 \mathrm{ml} / \text { day; } 20 \% \text { MCT/LCT Fat emulsion (100 ml/Bot.) } 2 \text { Bot./Day. }\end{array}$} \\
\hline
\end{tabular}

$20 \%$ fat emulsion daily, available calories 725 or $907 \mathrm{kcal}$ (PPN-A and B formulas). Two PPN formulas contained 41 or 45 grams of protein, respectively. Both formulations contain 40 grams of fat, multivitamin and trace elements (Zinc, Iodine, Copper, Manganese, Chromium). Zinc supplied for each patient $5.7 \mathrm{mg}$ per day for post-operative wound healing (Figure 1). PPN through an intravenous line, in order to avoid thromboembolism changed the injection site every tree days. We also encouraged patients to eat by oral or enteral feeding as tolerated to maintain the integrity of the intestinal mucosa. The patient diet record was obtained by registered dietitians.

\subsection{Application of Post-Operative Nutrition Support}

TPN support was performed immediately depending on the patient hemodynamically was stable post-operatively, and then as the guts tolerance combined enteral nutrition support. If the patients can tolerance enteral nutrition we turn TPN into PPN formulas. Post-operative nutrition supports both PPN and TPN were running through the central venous catheters. Parenteral nutrition support until the patients could reach $70 \%$ of nutrition goal via gut was suspended.

\subsection{Statistical Analysis}

Data were analyzed by the SPSS version 12.0 (SPSS, Inc). The nutritional statuses between two groups were analyzed by Student's t-test. The individual differences in nutritional status before and after surgery were analyzed by Paired-t test. Data are presented as means $\pm S D$, and a $p$ value of $<0.05$ was taken to indicate a significant difference.

\section{Results and Discussion}

\subsection{Patients}

40 patients' data were collected and divided into 2 groups, PPPN $(\mathrm{n}=25)$ including 12 males and 13 females received pre-operative nutritional support, NonPPPN ( $\mathrm{n}=15)$ including 11 males and 4 females (Table 3). Both groups were malnutrition risk rectal cancer patients that have undergone restorative proctectomy with
Table 3. Two groups of patients nutritional status pre-operative.

\begin{tabular}{ccccc}
\hline & $\mathrm{n}$ & Age & MST score & Serum albumin (g/dl) \\
\hline PPPN & 25 & $63.8 \pm 11.6$ & $2.64 \pm 0.7$ & $3.3 \pm 0.47$ \\
Non-PPPN & 15 & $67.5 \pm 11.5$ & $2.47 \pm 0.74$ & $3.1 \pm 1.13$ \\
$\mathrm{p}$ & & 0.203 & 0.46 & 0.641 \\
\hline
\end{tabular}

For the two groups, no significant differences were found in age, MST score and serum albumin for pre-operative. Values are presented as number of patients or mean \pm SD. PPPN: pre-operative peripheral parenteral nutrition support. Non-PPPN: not received PPPN.

colo-anal anastomosis.

\subsection{Pre-Operative Nutritional Support}

PPPN group received pre-operative nutritional support for $5.6 \pm 2.6$ days. Patients were encouraged enteral feeding as tolerated, average intake $822.6 \pm 224.3 \mathrm{kcal}$ per day.

\subsection{Post-Operative Nutritional Support}

After surgery two groups both received TPN support immediately. Two patients of PPPN group (8\%) and eight patients of Non-PPPN group (53\%) couldn't switch TPN to PPN formulas after one week post-operative. Over $50 \%$ of Non-PPPN group the guts couldn't work well resulting poor outcomes and prolong hospital days.

\subsection{Nutrition Conditions and Outcomes}

For the two groups, no significant differences were found in age, MST score, serum albumin or one month body weight change for pre-operative (Table 3). Serum albumin were obviously decreased $(\mathrm{p}<0.05)$ on the third post-operative day for two groups (Figure 2), but PPPN serum albumin was $2.5 \pm 0.32 \mathrm{~g} / \mathrm{dl}$, significantly higher than non-PPPN $1.92 \pm 0.42 \mathrm{~g} / \mathrm{dl}(\mathrm{p}<0.01)$. For first ambulatory time, PPPN was $3.0 \pm 0.8$ days, significantly less than $4.9 \pm 2.4$ days of non-PPPN (p < 0.05). Post-operative hospital days were $18.2 \pm 10.5$ for PPPN, significantly less than non-PPPN $33.7 \pm 20.0$ days (p $<0.05$ ) (Table 4). As for post-operative infection rate, in PPPN group no one was infected, on the other hand, there were four patients $(26.7 \%)$ suffered sepsis in non- 


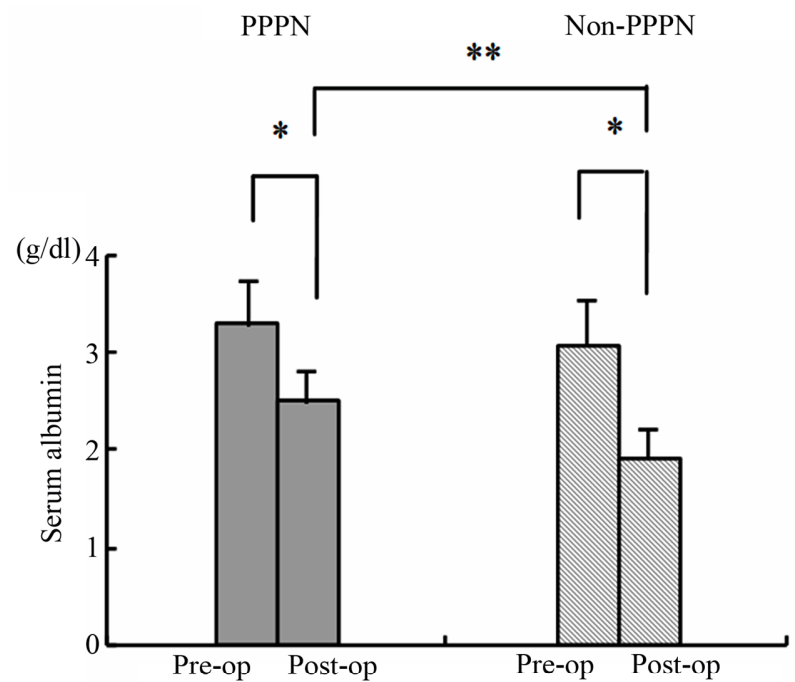

Figure 2. Pre- and post-operative serum albumin of PPPN and Non-PPPN groups were $3.3 \pm 0.47,2.5 \pm 0.32,3.1 \pm 1.13$ and $1.92 \pm 0.42$ respectively. The albumin obviously decreased on the third post-operative day for two groups, but PPPN group's serum albumin was significantly higher than non-PPPN group's; "p $<0.05,{ }^{* *}$ p $<0.01$. Pre-op: Pre-operative; Post-op: Post-operative.

Table 4. Two groups of patients nutritional status pos-toperative.

\begin{tabular}{cccc}
\hline & $\begin{array}{c}\text { PPPN } \\
(\mathrm{n}=25)\end{array}$ & $\begin{array}{c}\text { Non-PPPN } \\
(\mathrm{n}=15)\end{array}$ & $\mathrm{p}$ \\
\hline Serum albumin (g/dl) & $2.5 \pm 0.32$ & $1.92 \pm 0.42$ & 0.005 \\
First ambulatory time & $3.0 \pm 0.8$ & $4.9 \pm 2.4$ & 0.003 \\
Post-operative hospital days & $18.2 \pm 10.5$ & $33.7 \pm 20.0$ & 0.047 \\
\hline
\end{tabular}

PPPN serum albumin was $2.5 \pm 0.32 \mathrm{~g} / \mathrm{dl}$, significantly higher than nonPPPN $1.92 \pm 0.42 \mathrm{~g} / \mathrm{dl}(\mathrm{p}<0.01)$. For first ambulatory time, PPPN was 3.0 \pm 0.8 days, significantly less than $4.9 \pm 2.4$ days of non-PPPN $(\mathrm{p}<0.05)$. Post-operative hospital days were $18.2 \pm 10.5$ for PPPN, significantly less than non-PPPN $33.7 \pm 20.0$ days $(\mathrm{p}<0.05)$. Values are presented as number of patients or mean \pm SD. PPPN: pre-operative peripheral parenteral nutrition support. Non-PPPN: not received PPPN.

PPPN. One patient died during hospitalization (4.0\%) in PPPN, but non-PPPN had five dead (33.3\%) (Table 5). The results showed that malnourished patients who received pre-operative PPN support had recovered better than those without the support.

Surgical patients often have malnutrition and catabolism before major operation and followed by undergoing the stress and fasting. Nutritional support is necessary especially in severely malnourished patients who before surgery. Pre-operative nutritional support can improve the nutritional status, reduce complications of hypoalbuminemia, infection, pneumonia, sepsis and increased survival rate [9]. Oral intake or enteral nutritional support before major surgery is often less than expected because of guts dysfunction. Therefore, considering the advan-
Table 5. The sepsis and mortality rate of two groups.

\begin{tabular}{ccc}
\hline & $\begin{array}{c}\text { PPPN } \\
(\mathrm{n}=25)\end{array}$ & $\begin{array}{c}\text { Non-PPPN } \\
(\mathrm{n}=15)\end{array}$ \\
\hline Sepsis & $0 \%(0 / 25)$ & $26.7 \%(4 / 15)$ \\
Mortality & $4 \%(1 / 25)$ & $33.3 \%(5 / 15)$ \\
\hline
\end{tabular}

In post-operative infection rate, PPPN was no one infected but there were four patients (26.7\%) suffered sepsis in non-PPPN. One patient died during hospitalization (4.0\%) in PPPN, but non-PPPN had five deaths (33.3\%) PPPN: pre-operative peripheral parenteral nutrition support. Non-PPPN: not received PPPN.

tages of both intestinal and parenteral nutrition for the malnutrition abdominal surgery patients, enteral combined parenteral nutrition supplement is more beneficial to the patient.

TPN was a route often administered for the surgical patients to provide high and balanced nutrition. However, TPN requires a central venous catheter that has more risks of complication and inconvenient. Thus, PPN may be easier for malnutrition patients to short-term and urgent nutrition support. Traditionally, PPN supply most of the nutrients including glucose, amino acids and electrolytes that was more inadequate and was only for a shortterm (5 to 8 days) use. Therefore, if the PPN with fat emulsion infusion, vitamins and trace elements such as $\mathrm{Zn}, \mathrm{I}, \mathrm{Cu}, \mathrm{Mn}, \mathrm{Cr}$, etc. will be able to more effectively complement the nutritional needs of patients. Our study shows such enteral nutrition combined with hypo-calories with micronutrients and fat emulsion nutrients PPN applied to pre-operative nutritional support will be beneficial to the patient's tolerance for surgery.

In this study, 25 malnourished risk patients with preoperative nutritional support, although an average of no more than 7 days, but the prognosis was better than the patients with same condition of malnutrition that didn't receive nutritional support. PPPN patients plasma albumin was $2.50 \pm 0.32 \mathrm{~g} / \mathrm{dl}$, non-PPPN was $1.92 \pm 0.42 \mathrm{~g} / \mathrm{dl}$ in the post-operative ( $p<0.01)$. Which also makes the PPPN patients have better immunity that first ambulatory time and post-operative hospital days were significantly shortened. After surgery in both groups received postoperative parenteral nutritional support but the patients while receiving pre-operative nutritional support did receive significant benefits. The PPN can be a good shortterm pre-operative nutritional support approach.

Our PPN also has side effects of thromboembolism due to the high osmolarity solution of (approximately $735 \mathrm{mOsm} / \mathrm{L}$ ) injections often cause damage to peripheral vein wall. This study found that change the catheter injection site every 24 - 36 hours for patients, and minimize the mechanical interference of intravenous injection site, can effectively reduce the occurrence of thromboembolism. But there are still two patients in the 
implementation of pre-operative PPN two days because of the pain and refused to continue. Therefore, how to more effectively avoid thromboembolism is the pre-operative PPN another challenge. Some methods such as use a small amount of cortisol, a low dose of Heparin (1000 units/L) and the use of silicone elastomer catheters, etc., can be considered.

Pre-operative nutritional supports in the past most studies suggest 7 to 10 days [19]. Our study showed that pre-operative PPN support only $5.6 \pm 2.6$ days to achieve significant improvement in the prognosis, compared with past research refers to 7 - 10 days for short. This result can shorten the time of pre-operative nutritional support for patients with emergency medical conditions in particular meaningful. However, the chronically malnourished patients, pre-operative nutritional support should be adjusted to cater for different medical conditions such as diabetes, liver or kidney disease before surgery demand to achieve most effective nutritional support is the need of further research.

\section{Conclusion}

Nutritional support is a gradual process and promotes human body into anabolic stage. Pre-operative nutritional support should be after the nutritional assessment of the patient being admitted. The results of this study indicated that the time frame for hypo-calories with micronutrients and fat emulsion of pre-operative PPN support is merely $5.6 \pm 2.6$ days, shorter than previous studies, which is about 7 - 10 days and can significantly improve postoperative prognosis. It is critical to shorten the waiting for the surgery to reduce patients discomfort and reduce the complication rate.

\section{Acknowledgements}

The authors appreciate the staffs in the Nutrition Support Team and Cancer Registry Team of Sin-Lau hospital for their cooperation and support.

\section{REFERENCES}

[1] G. F. Reinhardt, J. W. Myscofski, D. B. Wilkens, P. B. Dobrin, J. E. Mangan Jr. and R. T. Stannard, "Incidence and Mortality of Hypoalbuminemic Patients in Hospitalized Veterans," JPEN-Journal of Parenteral and Enteral Nutrition, Vol. 4, No. 4, 1980, pp. 357-359. doi: $10.1177 / 0148607180004004357$

[2] A. S. Detsky, J. P. Baker, K. O’Rourke, N. Johnston, J. Whitwell, R. A. Mendelson and K. N. Jeejeebhoy, "Predicting Nutrition-Associated Complications for Patients Undergoing Gastrointestinal Surgery," JPEN-Journal of Parenteral and Enteral Nutrition, Vol. 11, No. 5, 1987, pp. 440-446. doi:10.1177/0148607187011005440
[3] J. A. Windsor and G. L. Hill, "Weight Loss with Physiologic Impairment. A Basic Indicator of Surgical Risk,” Annals of Surgery, Vol. 207, No. 3, 1988, pp. 290-296. doi:10.1097/00000658-198803000-00011

[4] H. Yamanaka, M. Nishi, T. Kanemaki, N. Hosoda, K. Hioki and M. Yamamoto, "Preoperative Nutritional Assessment to Predict Postoperative Complication in Gastric Cancer Patients,” JPEN-Journal of Parenteral and Enteral Nutrition, Vol. 13, No. 3, 1989, pp. 286-291. doi:10.1177/0148607189013003286

[5] J. M. Kinney, "Metabolic Responses of the Critically Ill Patient," Critical Care Clinics, Vol. 11, No. 3, 1995, pp. 569-585.

[6] S. Klein, J. Kinney, K. Jeejeebhoy, D. Alpers, M. Hellerstein, M. Murray and P. Twomey, "Nutrition Support in Clinical Practice: Review of Published Data and Recommendations for Future Research Directions. National Institutes of Health, American Society for Parenteral and Enteral Nutrition, and American Society for Clinical Nutrition," JPEN-Journal of Parenteral and Enteral Nutrition, Vol. 21, No. 3, 1997, pp. 133-156. doi:10.1177/0148607197021003133

[7] J. L. Mullen, M. H. Gertner, G. P. Buzby, G. L. Goodhart and E. F. Rosato, "Implications of Malnutrition in the Surgical Patient,” Archives of Surgery, Vol. 114, No. 2, 1979, pp. 121-125.

doi:10.1001/archsurg.1979.01370260011001

[8] J. Gibbs, W. Cull, W. Henderson, J. Daley, K. Hur and S. F. Khuri, "Preoperative Serum Albumin Level as a Predictor of Operative Mortality and Morbidity: Results from the National VA Surgical Risk Study,” Archives of Surgery, Vol. 134, No. 1, 1999, pp. 36-42. doi:10.1001/archsurg.134.1.36

[9] R. M. Salvino, R. S. Dechicco and D. L. Seidner, "Perioperative Nutrition Support: Who and How," Cleveland Clinic Journal of Medicine, Vol. 71, No. 4, 2004, pp. 345-351. doi:10.3949/ccjm.71.4.345

[10] J. Alverdy, H. S. Chi and G. F. Sheldon, "The Effect of Parenteral Nutrition on Gastrointestinal Immunity. The Importance of Enteral Stimulation," Annals of Surgery, Vol. 202, No. 6, 1985, pp. 681-684. doi:10.1097/00000658-198512000-00003

[11] K. A. Kudsk, J. Li and K. B. Renegar, "Loss of Upper Respiratory Tract Immunity with Parenteral Feeding," Annals of Surgery, Vol. 223, No. 6, 1996, pp. 629-635, 635-688. doi:10.1097/00000658-199606000-00001

[12] J. Meyer, R. W. Yurt, R. Duhaney, D. G. Hesse, K. J. Tracey, Y. Fong, D. Richardson, S. Calvano, P. Dineen, G. T. Shires, et al., "Differential Neutrophil Activation before and after Endotoxin Infusion in Enterally versus Parenterally Fed Volunteers,” Surgery, Gynecology \& Obstetrics, Vol. 167, No. 6, 1988, pp. 501-509.

[13] J. MacFie, N. P. Woodcock, M. D. Palmer, A. Walker, S. Townsend and C. J. Mitchell, “Oral Dietary Supplements in Pre- and Postoperative Surgical Patients: A Prospective and Randomized Clinical Trial,” Nutrition, Vol. 16, No. 9, 2000, pp. 723-728. doi:10.1016/S0899-9007(00)00377-4

[14] M. H. Torosian, "Perioperative Nutrition Support for 
Patients Undergoing Gastrointestinal Surgery: Critical Analysis and Recommendations," World Journal of Surgery, Vol. 23, No. 6, 1999, pp. 565-569. doi:10.1007/PL00012348

[15] M. Ferguson, S. Capra, J. Bauer and M. Banks, "Development of a Valid and Reliable Malnutrition Screening Tool for Adult Acute Hospital Patients,” Nutrition, Vol. 15, No. 6, 1999, pp. 458-464. doi:10.1016/S0899-9007(99)00084-2

[16] E. Isenring, G. Cross, L. Daniels, E. Kellett and B. Koczwara, "Validity of the Malnutrition Screening Tool as an Effective Predictor of Nutritional Risk in Oncology Outpatients Receiving Chemotherapy," Support Care Cancer, Vol. 14, No. 11, 2006, pp. 1152-1156. doi:10.1007/s00520-006-0070-5

[17] E. A. Isenring, J. D. Bauer, M. Banks and D. Gaskill,
"The Malnutrition Screening Tool is a Useful Tool for Identifying Malnutrition Risk in Residential Aged Care," Journal of Human Nutrition Dietetics, Vol. 22, No. 6, 2009, pp. 545-550. doi:10.1111/j.1365-277X.2009.01008.X

[18] A. Lev-Ran, M. Johnson, D. L. Hwang, J. Askanazi, C. Weissman and M. Gersovitz, "Double-Blind Study of Glycerol vs Glucose in Parenteral Nutrition of Postsurgical Insulin-Treated Diabetic Patients," JPEN-Journal of Parenteral and Enteral Nutrition, Vol. 11, No. 3, 1987, pp. 271-274. doi:10.1177/0148607187011003271

[19] "Perioperative Total Parenteral Nutrition in Surgical Patients. The Veterans Affairs Total Parenteral Nutrition Cooperative Study Group," New England Journal of Medicine, Vol. 325, 1991, pp. 525-532. doi:10.1056/NEJM199108223250801 